Check for updates

Cite this: RSC Adv., 2018, 8, 24370

\title{
Anisotropic growth of gas-liquid precipitated ceria mesocrystals to wires several micrometers in length
}

\author{
Yuta Kubota, (D) Tetsuo Kishi, Tetsuji Yano and Nobuhiro Matsushita* \\ Ceria $\left(\mathrm{CeO}_{2}\right)$ wires with lengths of $6 \mu \mathrm{m}$ and diameters of tens of nanometers are fabricated through the \\ anisotropic growth of mesocrystals. In the gas-liquid precipitation process, an aqueous $\mathrm{Ce}\left(\mathrm{NO}_{3}\right)_{3}$ \\ solution is used as a starting material and $\mathrm{NH}_{3}$ gas is used to induce $\mathrm{CeO}_{2}$ precipitation at the gas-liquid \\ interface. $\mathrm{CeO}_{2}$ mesocrystals, formed by this process at $60{ }^{\circ} \mathrm{C}$, grow in the direction of $\langle 011\rangle$ into \\ micrometer length wires exposing $\{001\}$ and $\{011\}$ on their side walls. It is shown that the initial $\mathrm{pH}$ of the \\ starting material solution is a key parameter to attain anisotropic growth of the $\mathrm{CeO}_{2}$ mesocrystals. We \\ thus propose the formation mechanism of micrometer length- $\mathrm{CeO}_{2}$ wires from mesocrystals.
}

Received 22nd June 2018 Accepted 27th June 2018

DOI: $10.1039 / c 8 r a 05362 f$

rsc.li/rsc-advances using $\mathrm{NaOH}$ at $130^{\circ} \mathrm{C}$, and then $\mathrm{CeO}_{2}$ nanotubes were prepared by ultrasonic synthesis using $\mathrm{H}_{2} \mathrm{O}_{2}$ at room temperature. ${ }^{30}$ Although this synthesis could prepare $\mathrm{CeO}_{2}$ without impurities, a hydroxide was initially formed before obtaining the oxide. Alternatively, Gu and Meng reported that SDC nanowires and nanotubes could be prepared directly from aqueous Ce and Sm salts without impurities by a gas-liquid precipitation process. ${ }^{31}$ In this process, gas phase alkaline agents were added into a metal ions solution for the precipitation reaction. This process, which uses gaseous ammonia, is different from a general precipitation. A direct preparation without incorporating impurities is advantageous for preparing oxides, but the mechanism for the 1D shape formation remains unknown.

In this study, $1 \mathrm{D}$ structured $\mathrm{CeO}_{2}$ several micrometers in length was prepared by a gas-liquid precipitation process under various conditions, that is, synthesis temperature, the kind of Ce salt, and initial $\mathrm{pH}$ of the aqueous Ce salt. The study revealed that the formation of $\mathrm{CeO}_{2}$ "mesocrystals" is essential for anisotropic growth of $1 \mathrm{D}$ shaped $\mathrm{CeO}_{2}$ wire. The mesocrystals mean mesoscale self-assembled structure and transformation of nanostructures or superstructures of nanocrystals with a specific crystallographic orientation..$^{32,33}$ The study will open up a way for the anisotropic growth of mesostructured functional materials.

\section{Experimental method}

$\mathrm{CeO}_{2}$ wires were prepared by the gas-liquid precipitation process shown in Fig. 1. This process was carried out by vaporizing $\mathrm{NH}_{3}$ from an $\mathrm{NH}_{3}$ gas generating solution, and the generated gas reached the surface of the starting material solution, which induced precipitation at the gas-liquid interface. The starting material solution was prepared by dissolving $2 \mathrm{mmol}$ of $\mathrm{Ce}\left(\mathrm{NO}_{3}\right)_{3} \cdot 6 \mathrm{H}_{2} \mathrm{O}$ (Wako Pure Chemical Industries, Ltd., Japan, $99.5 \%$ ) and $\mathrm{CeCl}_{3} \cdot 7 \mathrm{H}_{2} \mathrm{O}$ (Wako Pure Chemical
Department of Materials Science and Engineering, Tokyo Institute of Technology, 2-12-1 Ookayama, Meguro, Tokyo 152-8550, Japan. E-mail: matsushita.n.ab@m. titech.ac.jp 


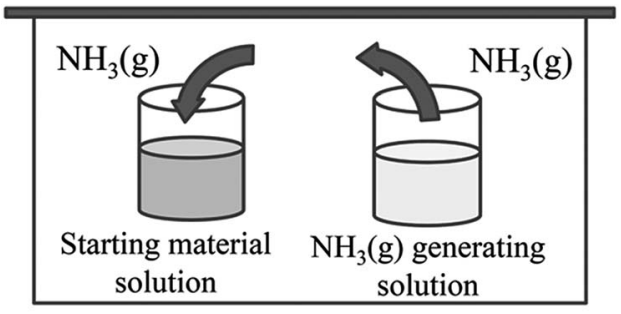

Sealed vessel at 7,25 and $60^{\circ} \mathrm{C}$

Fig. 1 Schematic image of the gas-liquid precipitation process.

Industries, Ltd., Japan, 97.0\%) into deionized water (40 mL) at $25{ }^{\circ} \mathrm{C}$. Aqueous $\mathrm{NH}_{3}$ (Wako Pure Chemical Industries, Ltd., Japan, $40 \mathrm{~mL}, 28 \mathrm{wt} \%$ ) was used as the $\mathrm{NH}_{3}$ gas generating solution. The $\mathrm{pH}$ values of aqueous solutions of $0.05 \mathrm{M}$ $\mathrm{Ce}\left(\mathrm{NO}_{3}\right)_{3}$ and $0.05 \mathrm{M} \mathrm{CeCl}_{3}$ were 4.6 and 5.7 , respectively. The difference in $\mathrm{pH}$ of the nitrate and chloride solutions directly affected the wire $\mathrm{CeO}_{2}$ formation. Therefore, the experiment using $\mathrm{CeCl}_{3}$ was conducted after adjusting the $\mathrm{pH}$ to $4.6 \mathrm{using}$ $\mathrm{HCl}$. Containers of the starting material solution and the $\mathrm{NH}_{3}$ gas generating solution were placed into a sealed vessel, and were maintained at temperatures of 7,25 , and $60{ }^{\circ} \mathrm{C}$ for 3 and 10 days. The obtained precipitates were then purified 3 times using deionized water, and were dried at $60{ }^{\circ} \mathrm{C}$ for 1 day. All synthesis conditions are listed in Table 1.

The purified samples were characterized by powder X-ray diffraction (XRD) analyses, field emission-scanning electron microscopy (FE-SEM), and transmission electron microscopy (TEM). Powder XRD analyses were performed by a RINT 2100 diffractometer (Rigaku Co., Japan) with a $\mathrm{CuK} \alpha$ radiation source $(\lambda=1.54056 \AA)$. The operating current and voltage for the analyses were $40 \mathrm{~mA}$ and $40 \mathrm{kV}$, respectively, and the scanning rate was set as $2 \mathrm{deg} \mathrm{min}^{-1}$. A non-reflecting plate made of single crystal silicon was used as a sample holder. FE-SEM observations were performed by a S-4500 scanning electron microscope (Hitachi Ltd., Japan) at an accelerating voltage of 15 $\mathrm{kV}$. The samples were coated with a Pt-Pd layer by sputtering before the observations. TEM observations were performed by a H-8100 transmission electron microscope (Hitachi Ltd., Japan) at an accelerating voltage of $200 \mathrm{kV}$ and current of $8 \mu \mathrm{A}$. The TEM grid samples to be observed were prepared by dropping sample dispersions in $\mathrm{H}_{2} \mathrm{O}$ on an elastic carbon support film (ELS-C10, Okenshoji Co., Ltd., Japan). Here, these dispersions were produced by ultrasonication for several seconds. Three software programs were used to investigate the formation

Table 1 Synthesis conditions and sample names

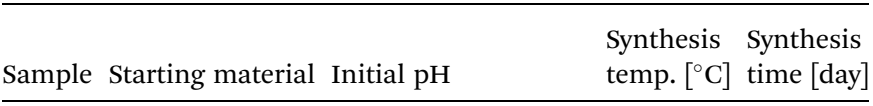

$\begin{array}{lllll}\text { (a) } & \mathrm{Ce}\left(\mathrm{NO}_{3}\right)_{3} \cdot 6 \mathrm{H}_{2} \mathrm{O} & 4.6 & 25 & 3 \\ \text { (b) } & \mathrm{Ce}\left(\mathrm{NO}_{3}\right)_{3} \cdot 6 \mathrm{H}_{2} \mathrm{O} & 4.6 & 25 & 10 \\ \text { (c) } & \mathrm{Ce}\left(\mathrm{NO}_{3}\right)_{3} \cdot 6 \mathrm{H}_{2} \mathrm{O} & 4.6 & 7 & 3 \\ \text { (d) } & \mathrm{Ce}\left(\mathrm{NO}_{3}\right)_{3} \cdot 6 \mathrm{H}_{2} \mathrm{O} & 4.6 & 60 & 3 \\ \text { (e) } & \mathrm{CeCl}_{3} \cdot 7 \mathrm{H}_{2} \mathrm{O} & 5.7 & 60 & 3 \\ \text { (f) } & \mathrm{CeCl}_{3} \cdot 7 \mathrm{H}_{2} \mathrm{O} & 4.6 \text { (adjusted by } \mathrm{HCl}) & 60 & 3\end{array}$

mechanism of the $\mathrm{CeO}_{2}$ wires. These were "ImageJ" (Rasband, National Institutes of Health, USA), ${ }^{34}$ "ReciPro" (Seto, Kobe University, Japan), and "VESTA" (Momma and Izumi)..$^{35}$ ImageJ was used to obtain the fast Fourier transform (FFT) diffraction patterns of the prepared $\mathrm{CeO}_{2}$ nanoparticles from their TEM images. The obtained FFT diffraction patterns were matched with those of the $\mathrm{CeO}_{2}$ single crystal. VESTA was used to draft the crystal morphologies of the $\mathrm{CeO}_{2}$ nanoparticles from the data obtained by ReciPro.

\section{Results and discussion}

This paper revealed two unique points. (1) Mesocrystals were formed before $\mathrm{CeO}_{2}$ wires formation and (2) initial $\mathrm{pH}$ is one of the intrinsic conditions to obtain $\mathrm{CeO}_{2}$ wires by gas-liquid precipitation process.

Fig. 2 shows the XRD patterns of the samples prepared by the gas-liquid precipitation process on the different conditions listed in Table 1 . The patterns corresponded to those of reference $\mathrm{CeO}_{2}$ (JCPDS card no. 43-1002). The average crystallite sizes of the precipitates were calculated at the strongest peaks (111) using the Scherrer equation described below:

$$
D=0.9 \lambda / \beta \cos \theta
$$

where $D$ is the average crystallite size, and $\lambda, \beta$, and $\theta$ are the $\mathrm{X}$ ray wavelength, the width of the (111) peak at half of the maximum intensity, and the angle of the (111) peak, respectively. The calculated $D$ values are shown in Fig. 2. The size increased with an increase in the synthesis temperature, as shown in Fig. 2(a), (c), and (d). In addition, the initial pH of the aqueous $\mathrm{CeCl}_{3}$ had an influence on the average crystallite size, as shown in Fig. 2(e) and (f).

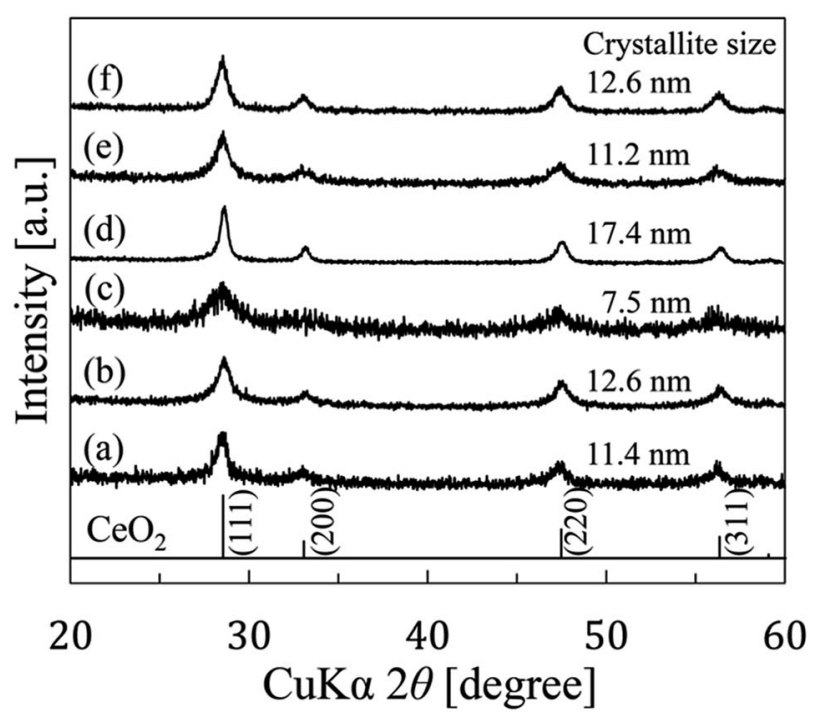

Fig. 2 XRD patterns of the $\mathrm{CeO}_{2}$ nanoparticles prepared by the gasliquid precipitation process under various conditions using $\mathrm{Ce}\left(\mathrm{NO}_{3}\right)_{3}$ solution (a) at $25^{\circ} \mathrm{C}$ for 3 days, (b) at $25^{\circ} \mathrm{C}$ for 10 days, (c) at $7{ }^{\circ} \mathrm{C}$ for 3 days, (d) at $60^{\circ} \mathrm{C}$ for 3 days, and using a $\mathrm{CeCl}_{3}$ solution (e) at $60^{\circ} \mathrm{C}$ for 3 days without the initial $\mathrm{pH}$ adjustment, and (f) at $60^{\circ} \mathrm{C}$ for 3 days with the initial $\mathrm{pH}$ adjustment to $\mathrm{pH} 4.6$ using $\mathrm{HCl}$. 
In addition to the estimation of the crystallite size, we observed the shapes of the prepared samples by FE-SEM, as shown in Fig. 3. The shapes of the precipitates were different for the various synthesis conditions. $\mathrm{CeO}_{2}$ precipitates accumulated as rods for the conditions (a) and (f), and wires with lengths of several micrometers for the conditions (b) and (d). However, the $\mathrm{CeO}_{2}$ precipitates had a plate-like structure and an unremarkable particle structure for the conditions (c) and (e). The lengths and diameters were (a) 0.1-0.3 $\mu \mathrm{m}$ and 5-10 $\mathrm{nm}$, (b) 1.4-3.4 $\mu \mathrm{m}$ and 5-40 nm, (d) 1.0-5.7 $\mu \mathrm{m}$ and 5-50 nm, and (f) 0.6-2.8 $\mu \mathrm{m}$ and 100-200 $\mathrm{nm}$, respectively. Comparing (a) and (b), the synthesis time had an influence on the length of samples. In the case of (a) and (d), the synthesis temperature also had an influence on the length of the samples. There was a difference between (e) and (f) in the initial pH of the staring material solution. From this difference, it was evident that the initial $\mathrm{pH}$ of the starting material solution has an effect on the anisotropic growth of precipitates. The $\mathrm{pH}$ value of 4.6 was effective for obtaining $1 \mathrm{D}$ growth compared with a value of 5.7.
In addition, a wire shape with a high aspect ratio was prepared more easily using $\mathrm{Ce}\left(\mathrm{NO}_{3}\right)_{3}$ rather than $\mathrm{CeCl}_{3}$.

Fig. 4 shows the change in $\mathrm{pH}$ of the starting material $\left(\mathrm{Ce}\left(\mathrm{NO}_{3}\right)_{3}\right)$ solution at $60{ }^{\circ} \mathrm{C}$ at various times. Each $\mathrm{pH}$ was measured at $25{ }^{\circ} \mathrm{C}$ after cooling. The $\mathrm{pH}$ values were almost constant from $1 / 6$ to $5 \mathrm{~min}$ at 6.2 , and then the $\mathrm{pH}$ value increased from 5 to $30 \mathrm{~min}$. The $\mathrm{pH}$ value of 9.5 gradually increased to $\mathrm{pH} 11.3$ after 3 days.

Fig. 5(a)-(d) shows TEM images and the FFT patterns of the $\mathrm{CeO}_{2}$ nanoparticles prepared at $60{ }^{\circ} \mathrm{C}$ for (a) $10 \mathrm{~min}$, (b) $2 \mathrm{~h}$, (c) $8 \mathrm{~h}$, and (d) 3 days by gas-liquid precipitation using $\mathrm{Ce}\left(\mathrm{NO}_{3}\right)_{3}$ as the starting material. Since the precipitates in the sample prepared for $5 \mathrm{~min}$ was dissolved during centrifugation and could not be observed by TEM, the sample prepared for $10 \mathrm{~min}$ was observed instead. In Fig. 5(a), the aggregated nanoparticles of 2-5 $\mathrm{nm}$ in diameter were observed without having an oriented attachment. However, the sample prepared for $2 \mathrm{~h}$ was a mesocrystal, in which nanoparticles had an oriented attachment at $\{111\}$ as seen in the FFT patterns. The sample prepared
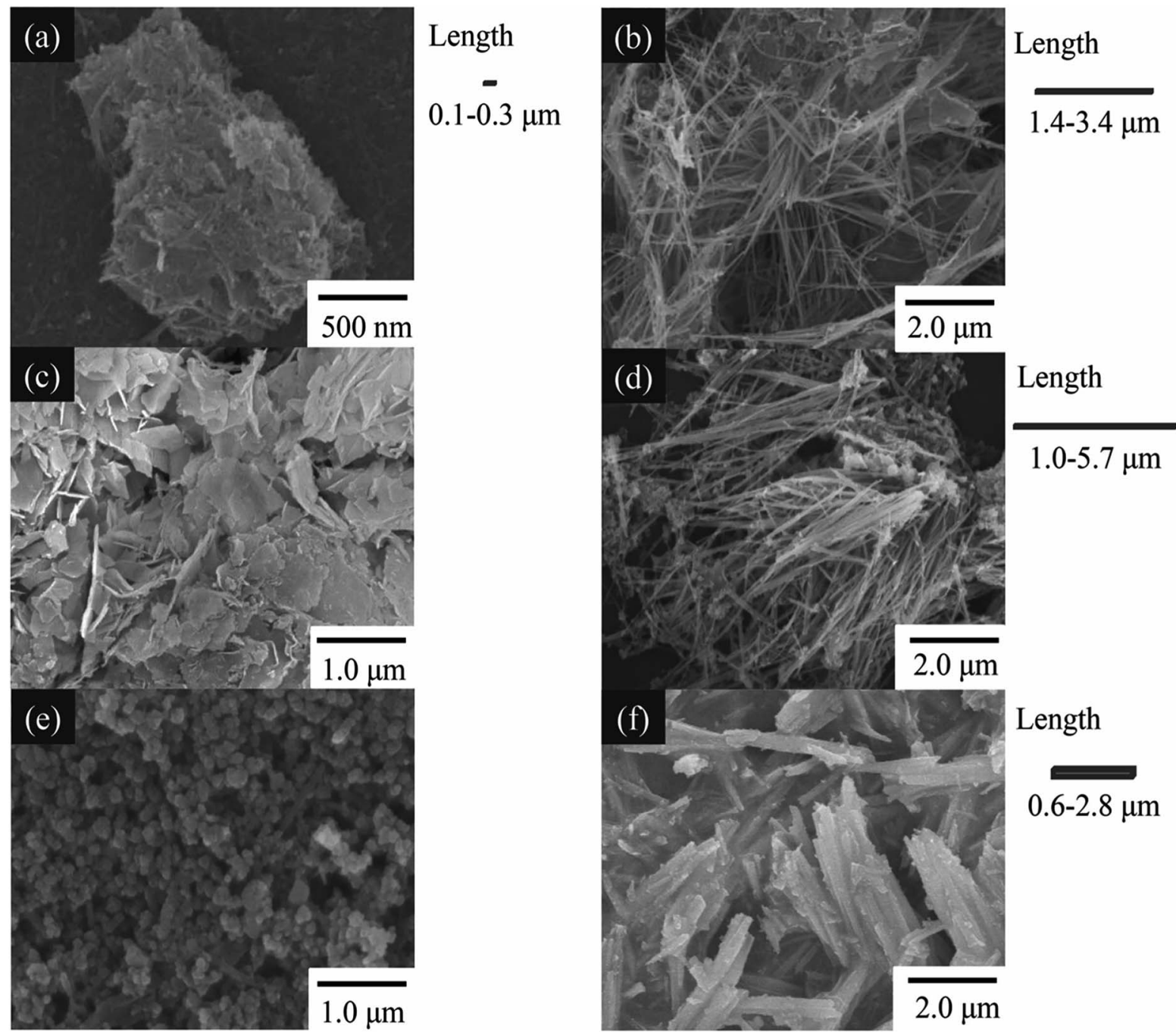

Fig. 3 SEM images of the ceria nanoparticles prepared by the gas-liquid precipitation process under various condition using $\mathrm{Ce}\left(\mathrm{NO}_{3}\right)_{3}$ solution (a) at $25^{\circ} \mathrm{C}$ for 3 days, (b) at $25^{\circ} \mathrm{C}$ for 10 days, (c) at $7{ }^{\circ} \mathrm{C}$ for 3 days, (d) at $60^{\circ} \mathrm{C}$ for 3 days, and using a CeCl ${ }_{3}$ solution (e) at $60{ }^{\circ} \mathrm{C}$ for 3 days without the initial $\mathrm{pH}$ adjustment, and (f) at $60^{\circ} \mathrm{C}$ for 3 days with the initial $\mathrm{pH}$ adjustment to $\mathrm{pH} 4.6$ using $\mathrm{HCl}$. 


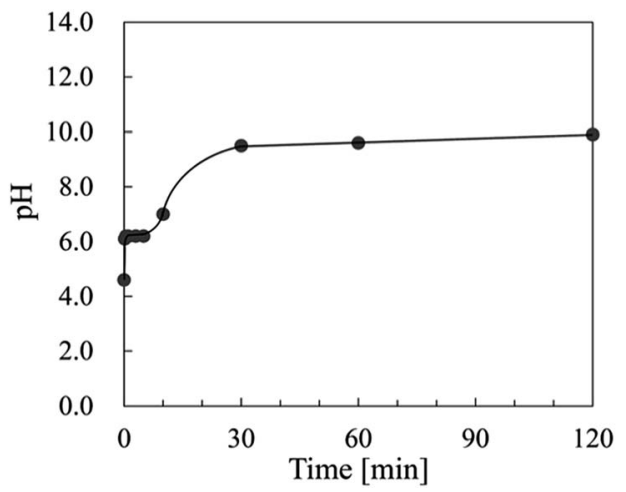

Fig. 4 Change in $\mathrm{pH}$ of the starting material $\left(\mathrm{Ce}\left(\mathrm{NO}_{3}\right)_{3}\right)$ solution at $60{ }^{\circ} \mathrm{C}$ for various times. Each $\mathrm{pH}$ was measured at $25^{\circ} \mathrm{C}$ after cooling

for $8 \mathrm{~h}$ was also a mesocrystal composed of nanoparticles that looked like hexagonal plates. The sample prepared for 3 days had a wire shape that showed anisotropic growth in the $\langle 011\rangle$ direction. The FFT image revealed that $\{001\}$ and $\{011\}$ were exposed on the wire surfaces.

In this research, the mesocrystal was not formed for $10 \mathrm{~min}$ after the commencement of the reaction. The products started to crystallize at the gas-liquid interface in this process. As was previously described, the samples prepared for $5 \mathrm{~min}$ at the gasliquid interface were dissolved during centrifugation. From these facts, resolution of the particles prepared at the gas-liquid interface was achieved because of $\mathrm{pH}$ gradation from the gasliquid interface to the bottom of the container. According to the literature, ${ }^{36}$ the surface energies of $\mathrm{CeO}_{2}$ surfaces are in the order of $\{001\}>\{011\}>\{111\}$. Therefore, $\{001\}$ and $\{011\}$ are dissolved more easily than $\{111\}$. This indicated that resolution of the precipitates prepared for 10 min after commencement of the reaction, which had $\{001\}$ and $\{011\}$ surfaces, was achieved with going down to the bottom of the container. In other words, the $\mathrm{pH}$ at the bottom of the container was sufficiently low for resolution of the precipitates with the $\{001\}$ and $\{011\}$ surfaces 10 min after commencement of the reaction. The dissolved $\mathrm{Ce}^{4+}$ was adsorbed on the remaining $\mathrm{CeO}_{2}\{111\}$ surface, and the $\{111\}$ exposed nanocrystals were formed as a result. The $\mathrm{pH}$ of the container almost became saturated and became basic after a reaction time of $30 \mathrm{~min}$, as shown in Fig. 4 . The increase in the concentration of $\mathrm{OH}^{-}$prevented the resolution of $\{001\}$ and $\{011\}$. Therefore, it was assumed that $\{001\}$ and $\{011\}$ were formed on the $\{111\}$-oriented $\mathrm{CeO}_{2}$ nanocrystals after a reaction time of $30 \mathrm{~min}$. However, $\mathrm{CeO}_{2}\{001\}$ was first evident in the TEM observation of the sample prepared for $8 \mathrm{~h}$. We assumed the change in the morphology of the nanocrystals was delayed from the change in the $\mathrm{pH}$, since the nanocrystals grew very slowly by Ostwald ripening. As was mentioned previously, $\{001\}$ is more unstable than $\{111\}$, so the grown nanocrystals exposed $\{001\}$ surface in the mesocrystal reassembled to be attached to each other on $\{001\}$, and then mesocrystals composed of hexagonal plate-like nanocrystals were formed. Since the $\{001\}$ surface has a strong polarity, ${ }^{20,37} \mathrm{NO}_{3}{ }^{-}$ions are attracted to the $\{001\}$ surface, and they work as capping agents. ${ }^{38}$ Therefore, the oriented attachment on $\{001\}$ was stopped owing to the reassembly because of an increase in the ratio of the concentration of $\mathrm{NO}_{3}{ }^{-}$ions to the surface area of the $\{001\}$ surface. From the above, the oriented attachment on $\{111\}$ proceeded, and $\mathrm{CeO}_{2}$ wires, which grew in the $\langle 011\rangle$ direction, were formed as a result. We assumed the concentration of $\mathrm{NO}_{3}{ }^{-}$had an influence on the growth direction of the wire, whether $\langle 011\rangle$ or $\langle 001\rangle$, and on the thickness along $\langle 001\rangle$ of the $\langle 011\rangle$ grown wire.

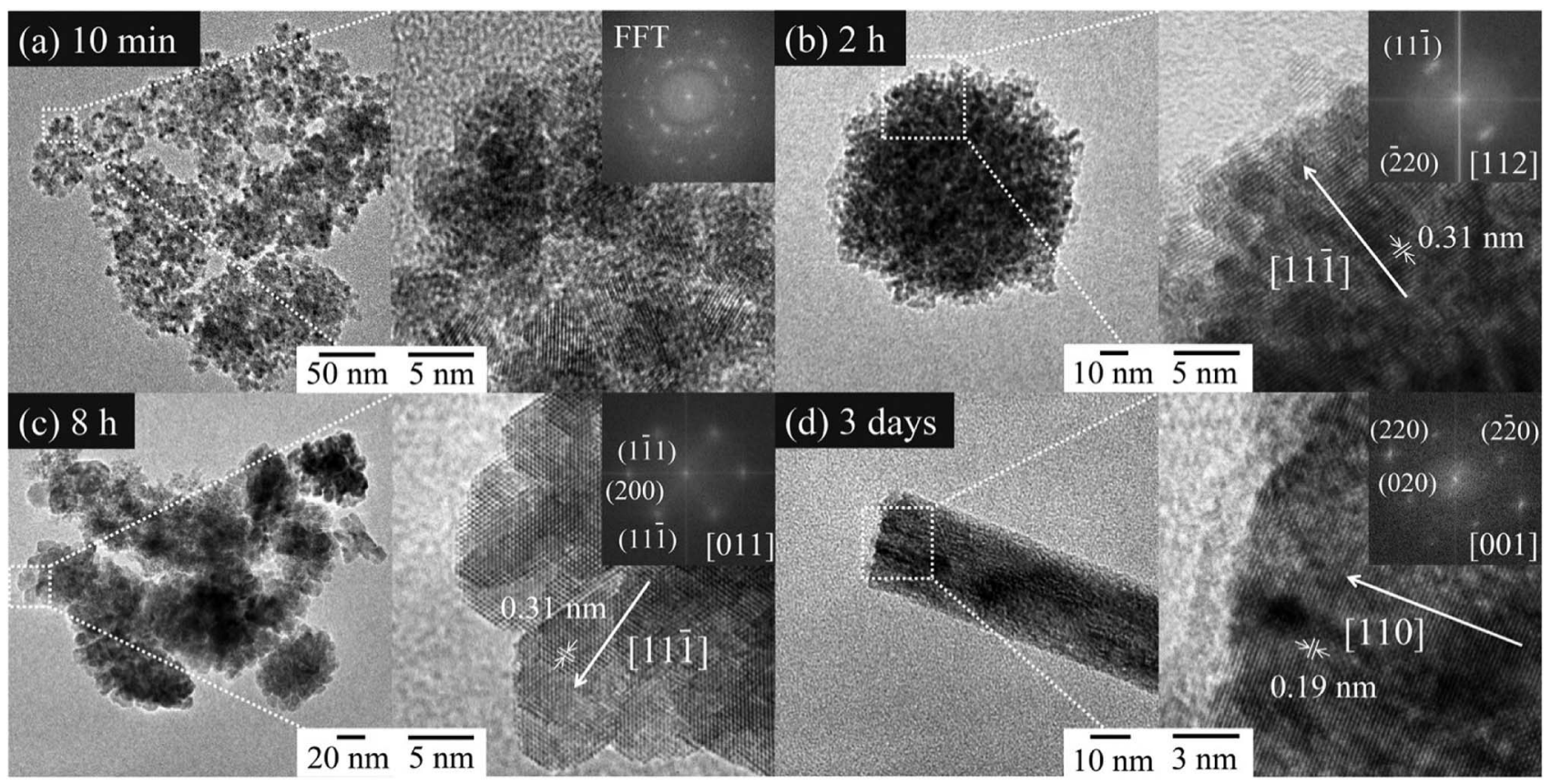

Fig. 5 TEM images and FFT analyses results of the $\mathrm{CeO}_{2}$ nanoparticles prepared by the gas-liquid precipitation process for various durations using $\mathrm{Ce}\left(\mathrm{NO}_{3}\right)_{3}$ at $60{ }^{\circ} \mathrm{C}$ for (a) $10 \mathrm{~min}$, (b) $2 \mathrm{~h}$, (c) $8 \mathrm{~h}$, and (d) 3 days. 
The $\mathrm{CeO}_{2}$ nanoparticles formed from 10 min to 3 days are illustrated in Fig. 6 using VESTA considering the TEM observations shown in Fig. 5. Mesocrystals composed of $\{111\}$ preferentially exposed nanocrystals were formed after $10 \mathrm{~min}$, when the $\mathrm{pH}$ was sufficiently low for the $\mathrm{Ce}^{4+}$ on $\{011\}$ and $\{001\}$ facets to be adsorbed on $\{111\}$ preferentially (STAGE $0 \rightarrow 1$ ). Once the $\mathrm{pH}$ was sufficiently increased for growth of $\{001\}$ and $\{011\}$, nanocrystals in the mesocrystals changed their growth direction from $\langle 001\rangle$ to both of $\langle 001\rangle$ and $\langle 111\rangle$. After formation of $\{001\}$, the nanocrystals in the mesocrystal reassembled to be attached to each other on $\{001\}$ owing to its high surface energy, and mesocrystals composed of hexagonal plate-like nanocrystals were formed (STAGE $1 \rightarrow 2$ ). Since the $\{001\}$ surface was stabilized by $\mathrm{NO}_{3}{ }^{-}$ions, the oriented attachment on $\{111\}$ proceeded (STAGE $2 \rightarrow 3$ ). The grown mesocrystals were continuously attached to each other on $\{111\}$ to have anisotropic growth in $\langle 011\rangle$, and $\mathrm{CeO}_{2}$ wires were formed (STAGE $3 \rightarrow 4$ ).

We propose that the resolution of the first nanocrystals in aggregates at low $\mathrm{pH}$ is an essential reaction for the formation of mesocrystals, which is required for $1 \mathrm{D}$ shaped $\mathrm{CeO}_{2}$ wires/rods formation. $\mathrm{CeO}_{2}$ rods were obtained from $\mathrm{CeCl}_{3}$ when the initial $\mathrm{pH}$ was sufficiently low at 4.6, as shown in Fig. 3(e) and (f). In addition, dissolution-recrystallization process is enhanced by the presence of $\mathrm{NO}_{3}{ }^{-} .^{38}$ Therefore, it was considered that mesocrystals were formed more easily using $\mathrm{Ce}\left(\mathrm{NO}_{3}\right)_{3}$ rather than $\mathrm{CeCl}_{3} \cdot \mathrm{CeO}_{2}$

\section{STAGE 0}

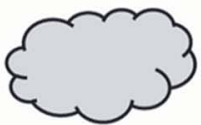

Aggregates of the initial crystals

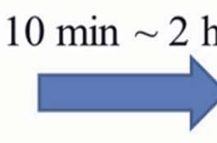

$\{111\}$
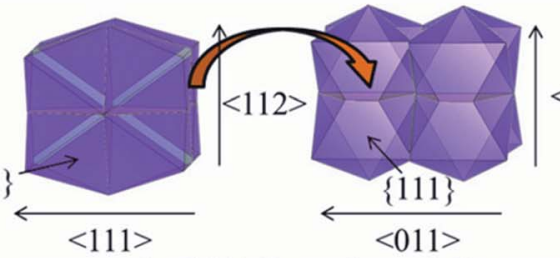
$<112>$

STAGE 1 Mesocrystal composed of $\{111\}$ preferentially exposed nanocrystals Growth of nanocrystals in mesocrystal

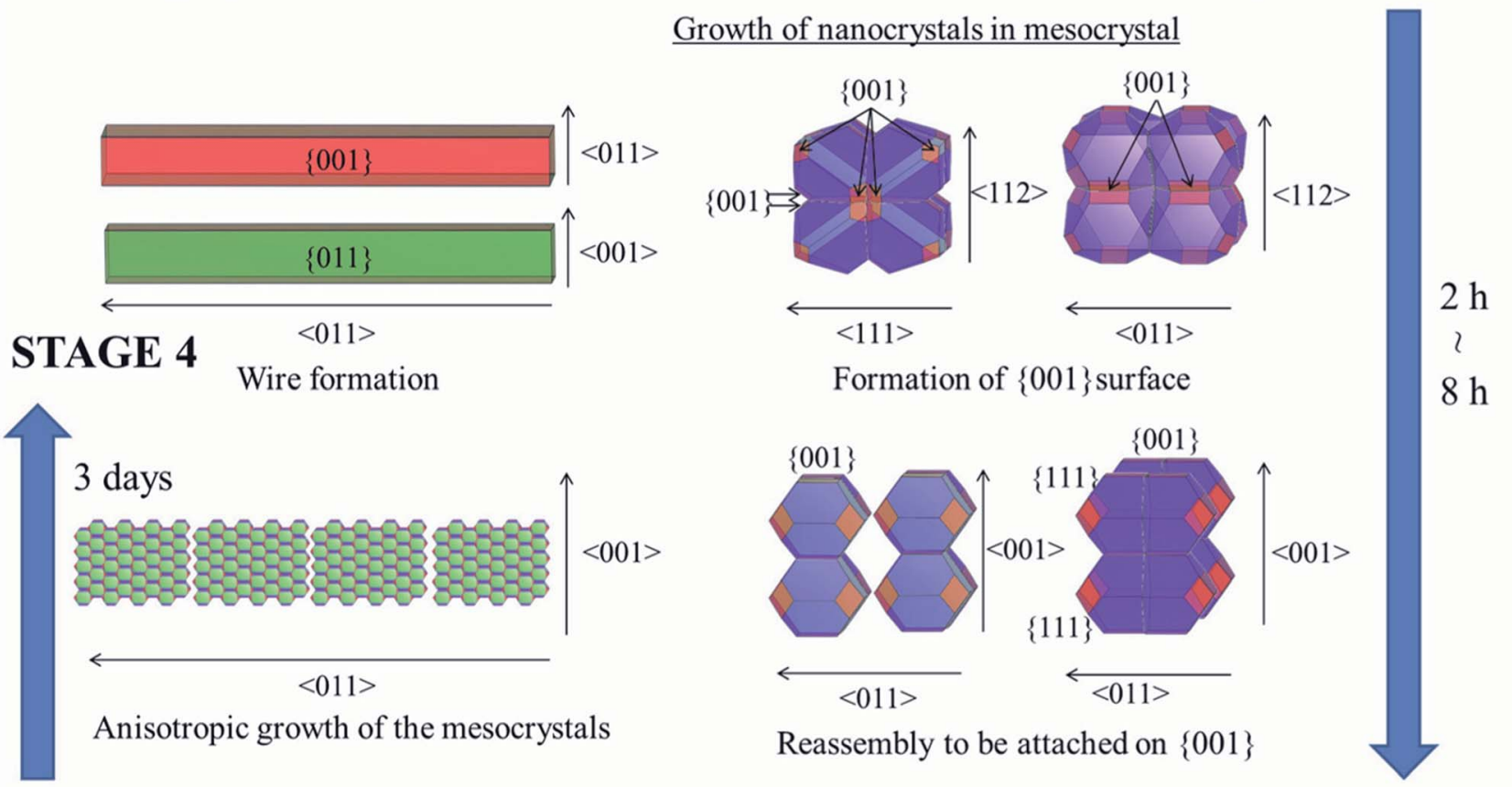

\section{STAGE 3}

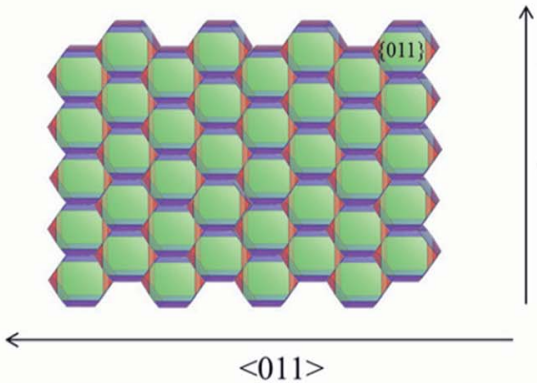

Oriented attachment of mesocrystals on $\{111\}$

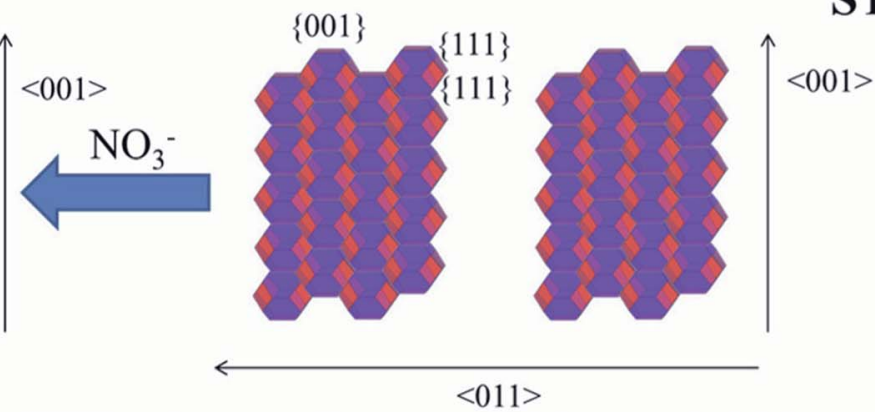

Mesocrystals composed of hexagonal plate-like nanocrystals

Fig. 6 Formation mechanism of several micron length $\mathrm{CeO}_{2}$ wire by the gas-liquid precipitation process (from STAGE 0 to 4). 
wires with a higher aspect ratio were formed from $\mathrm{Ce}\left(\mathrm{NO}_{3}\right)_{3}$, as shown in Fig. 3(d) and (f), even though the initial $\mathrm{pH}$ of the $\mathrm{CeCl}_{3}$ solution was adjusted to the same value to that of the $\mathrm{Ce}\left(\mathrm{NO}_{3}\right)_{3}$ solution. These experimental results were consistent with our formation mechanism proposed in this study.

\section{Conclusions}

Prepared $\mathrm{CeO}_{2}$ wires were formed from mesocrystals by $\{111\}$ oriented attachments. Hence, the formation of mesocrystals in the initial step of the reaction was a key point for the formation of $\mathrm{CeO}_{2}$ wires. Although it remains a challenge for future research to reveal the relationship between the morphologies of the prepared $\mathrm{CeO}_{2}$ and the change in the $\mathrm{pH}$ of the starting material solution, we found the initial $\mathrm{pH}$ of the starting material solution had an influence on the mesocrystals formation. The gas-liquid precipitation process developed in this study enabled the formation of micrometer length $\mathrm{CeO}_{2}$ wires using only ambient conditions. This green process opens a way for functional oxides to form their oriented mesocrystals depending on their surface energies and to transform into the designated shapes like wires and sheets.

\section{Conflicts of interest}

There are no conflicts to declare.

\section{Acknowledgements}

The authors are grateful to Professor Y. Seto (Kobe University, Japan) for his contribution in the "ReciPro" software used for matching the FFT diffraction patterns of the prepared $\mathrm{CeO}_{2}$ nanoparticles with those of the theoretical crystal $\mathrm{CeO}_{2}$. The authors also thank Professor Y. Kitamoto (Tokyo Institute of Technology, Japan) for assistance with the TEM analyses. This work was supported by MEXT Nanotechnology platform 12025014(F-17-IT-0017).

\section{References}

1 J. W. Dawicke and R. N. Blumenthal, J. Electrochem. Soc., 1986, 133, 904-909.

2 N. Izu, W. Shin, I. Matsubara and N. Murayama, Sens. Actuators, B, 2004, 100, 411-416.

3 C.-Y. Chen, K.-H. Chang, H.-Y. Chiang and S.-J. Shih, Sens. Actuators, B, 2014, 204, 31-41.

4 P. Pal, S. K. Pahari, A. Sinhamahapatra, M. Jayachandran, G. V. M. Kiruthika, H. C. Bajaja and A. B. Panda, $R S C A d v$, 2013, 3, 10837-10847.

5 C. L. Menéndez, Y. Zhou, C. M. Marin, N. J. Lawrence, E. B. Coughlin, C. L. Cheung and C. R. Cabrera, RSC Adv., 2014, 4, 33489-33496.

6 W. Zou, C. Ge, M. Lu, S. Wu, Y. Wang, J. Sun, Y. Pu, C. Tang, F. Gao and L. Dong, RSC Adv., 2015, 5, 98335-98343.

7 M. Ozawa, M. Kimura and A. Isogai, J. Alloys Compd., 1993, 193, 73-75.

8 J. Kašpar, P. Fornasiero and M. Graziani, Catal. Today, 1999, 50, 285-298.
9 S. Matsumoto, Catal. Today, 2004, 90, 183-190.

10 L. M. Cook, J. Non-Cryst. Solids, 1990, 120, 152-171.

11 T. Hoshino, Y. Kurata, Y. Terasaki and K. Susa, J. Non-Cryst. Solids, 2001, 283, 129-136.

12 P. Janoš, J. Ederer, V. Pilařová, J. Henych, J. Tolasz, D. Milde and T. Opletal, Wear, 2016, 362-363, 114-120.

13 Z. Fu, Q. Sun, D. Ma, N. Zhang, Y. An and Z. Yang, Appl. Phys. Lett., 2017, 111, 023903.

14 S. Zha, A. Moore, H. Abernathy and M. Liu, J. Electrochem. Soc., 2004, 151, A1128-A1133.

15 Y. Zheng, L. Wu, H. Gu, L. Gao, H. Chen and L. Guo, J. Alloys Compd., 2009, 486, 586-589.

16 H.-I. Chen and H.-Y. Chang, Colloids Surf., A, 2004, 242, 6169.

17 G. Wang, Q. Mu, T. Chen and Y. Wang, J. Alloys Compd., 2010, 493, 202-207.

18 F. Dang, K. Kato, H. Imai, S. Wada, H. Haneda and M. Kuwabara, Cryst. Growth Des., 2010, 10, 4537-4541.

19 T. Taniguchi, K. Katsumata, S. Omata, K. Okada and N. Matsushita, Cryst. Growth Des., 2011, 11, 3754-3760.

20 Y. Makinose, T. Taniguchi, K. Katsumata, K. Okada and N. Matsushita, Adv. Powder Technol., 2016, 27, 64-71.

21 Y. Liu, Z. Li, H. Xu and Y. Han, Catal. Commun., 2016, 76, 16.

22 L. Yan, R. Yu, J. Chen and X. Xing, Cryst. Growth Des., 2008, 8, 1474-1477.

23 Z. Ji, X. Wang, H. Zhang, S. Lin, H. Meng, B. Sun, S. George, T. Xia, A. E. Nel and J. I. Zink, ACS Nano, 2012, 6, 5366-5380.

24 A. Vantomme, Z.-Y. Yuan, G. Du and B.-L. Su, Langmuir, 2005, 21, 1132-1135.

25 Z.-Y. Yuan, V. Idakiev, A. Vantomme, T. Tabakova, T.-Z. Ren and B.-L. Su, Catal. Today, 2008, 131, 203-210.

26 R.-J. Qi, Y.-J. Zhu, G.-F. Cheng and Y.-H. Huang, Nanotechnology, 2005, 16, 2502-2506.

27 K. Nakagawa, Y. Tezuka, T. Ohshima, M. Katayama, T. Ogata, K. Sotowa, M. Katoh and S. Sugiyama, Adv. Powder Technol., 2016, 27, 2128-2135.

28 C. R. Li, Q. T. Sun, N. P. Lu, B. Y. Chen and W. J. Dong, J. Cryst. Growth, 2012, 343, 95-100.

29 Q. Dai, S. Bai, H. Li, W. Liu, X. Wang and G. Lu, CrystEngComm, 2014, 16, 9817-9827.

30 K. Zhou, Z. Yang and S. Yang, Chem. Mater., 2007, 19, 12151217.

31 L. N. Gu and G. Y. Meng, Mater. Res. Bull., 2008, 43, 15551561.

32 H. Cölfen and S. Mann, Angew. Chem., Int. Ed., 2003, 42, 2350-2365.

33 E. V. Sturm and H. Cölfen, Crystals, 2017, 7, 207.

34 C. A. Schneider, W. S. Rasband and K. W. Eliceiri, Nat. Methods, 2012, 9, 671-675.

35 K. Momma and F. Izumi, J. Appl. Crystallogr., 2008, 41, 653658.

36 M. Baudin, M. Wójcik and K. Hermansson, Surf. Sci., 2000, 468, 51-61.

37 H. F. Wardenga and A. Klein, Appl. Surf. Sci., 2016, 377, 1-8. 38 Q. Wu, F. Zhang, P. Xiao, H. Tao, X. Wang, Z. Hu and Y. Lü, J. Phys. Chem. C, 2008, 112, 17076-17080. 